\title{
SPECIFIC IDENTIFICATION OF TOADS AND FROGS BASED ON THE MOUTHPART CONFIGURATION OF THEIR TADPOLES
}

\author{
S. Yeboah and J.P. Deikumah \\ Department of Entomology and Wildife, \\ University of Cape Coast, Cape Coast, Ghana
}

\begin{abstract}
The mouth part configuration of the tadpoles of some anuran amphibians were examined using a dissecting microscope. Features examined included the tooth rows, oral disc, and the jaw sheath. Two different groups of tadpoles were collected and suitable pond conditions provided for them to metamorphose into adults. One group metamorphosed to Bufo regularis and the other to Hyperolius nasatus. The Bufo regularis tadpoles had a jaw sheath that was serrate and valley-sawed with a Labial Tooth row Formula (LTF) of 2(2)/3. The Hyperolius nasatus tadpoles on the other hand had a jaw sheath that was cuspate pointed with a Labial Tooth row Formula of 2(2)(3)/3(3). The findings from this study show that it is possible to identify frogs and toads from their tadpoles without having to look for the breeding adults in the wild.
\end{abstract}

Keywords: Mouthpart configuration, Bufo regularis, Hyperolius nasatus, Anuran, Labial Tooth row

\section{INTRODUCTION}

Frogs and toads are amphibians belonging to the Order Anura. The anurans have a life cycle with two distinct stages, typically living in water as young and on land as adults. Adult anurans lay large number of eggs in water or other moist places. The eggs hatch into small fish-like larvae called tadpoles.

The tadpoles of anurans have been found to show very unique characteristics such as mouthpart configuration, which is usually, made of jaw sheaths, labial tooth rows of varied appearances; and the oral disc shape. It has been found that color and shape cannot be used to identify tadpoles. For example, McDiarmid and Altig (2001) have stated that even con-specific tadpoles collected from turbid versus clear water vary tremendously in color, and tadpoles of the same species may differ in shape in still and flowing water (Jennings and Scott, 1993).

Examination of the small, complex oral apparatus of a tadpole provides major characteristics for species identification (Orton, 1953; McDiarmid and Altig, 2001) if every tadpole is critically ex- 
amined, one can tell specifically what species of toad or frog a particular tadpole will metamorphose into. Elsewhere, especially in Canada and the United State of America a "key system" has been developed based mainly on the mouthpart configuration of the tadpole and researchers are realizing that sampling tadpoles is usually an efficient viable means of assessing local biodiversity; tadpoles are present in aquatic habitats for longer periods than breeding adults and are often more easily collected (Barry and Schaffer, 1994; McDiarmid and Altig, 2001).

The present study focused specifically on the use of mouthpart configuration of tadpoles as basis for constructing a "key system" for classifying frogs and toads in Ghana.

\section{MATERIALS AND METHODS}

\section{Preparation of pond aquarium}

Two cemented ponds each of dimension $3 \mathrm{~m}$ by $3 \mathrm{~m}$ and $1 \mathrm{~m}$ deep were constructed in a shady area and a considerable volume of pond water containing algae was used to fill the ponds up to $60 \mathrm{~cm}$ high. The ponds were labeled A and B.

Two stones that stood a little above the water level in each pond were introduced into the ponds to serve as hiding places for the developing tadpoles, and pieces of wood and pebbles from a nearby pond some of which already contained algal growth were introduced into the pond to serve as source of food for the developing tadpoles. The open top of each of the ponds was partially covered with palm fronds to provide additional shade but open enough to allow flying insects such as mosquitoes and dragonflies to lay their eggs in the pond water. The eggs were expected to hatch into larvae and serve as animal protein for the tadpoles especially during limb development.

\section{Collection of tadpoles}

Tadpoles were collected from ponds around streams near the Kakum National Park into containers containing water from the same pond. Separation of the collected tadpoles into two groups (A and B) was done based on their superficial differences such as color, size and shape.

The tadpoles were then transported to the laboratory for microscopic examination. With the aid of a dissecting microscope, the mouthpart configurations such as labial tooth row and jaw sheets of three randomly selected individuals from each group were observed and recorded before they were introduced into their respective ponds. There was an initial introduction of 20 similar tadpoles each into the two ponds labeled A and B. Observation, monitoring and adjustment of the pond conditions such as temperature $\left(26-30^{\circ} \mathrm{C}\right)$, water levels $(0.8-1 \mathrm{~m})$ and supplementary food provision (lettuce) were carried out until metamorphosis of the tadpoles was completed (Horst, 1963).

\section{RESULTS}

The tadpoles in group A had an average body length of $1.2 \mathrm{~cm}$. The tadpoles in group A had mouthpart characteristics indicated in Table 1 and Fig. 1. The oral disc was emarginate (Fig. 1a.) and the jaw sheath serrate and valley shaped (Fig. 1b). They had 2 anterior labial tooth rows (LTR) with a gap in the second row (i.e. 2(2)). There were also 3 posterior labial tooth rows without a gap in any of them (i.e. 3) (Fig.1c). Two of the 20 tadpoles in group A died and 18 successfully metamorphosed into the same species, Bufo regularis in 22 days.

The tadpoles in group B had an average body length of $1.3 \mathrm{~cm}$. The tadpoles in group B had mouthpart characteristics as indicated in Table 2 and Fig. 2. They had an emarginate oral disc (Fig. 2a) and the jaw sheath was cuspate and pointed (Fig. 2b). They had 3 anterior labial tooth rows with gaps in the second and third rows (i.e. 3 (2) (3)), and 3 posterior labial tooth rows with a gap in the first tooth row (i.e. 3(1)) (Fig. 2c). Five individuals of this group died and 15 successfully metamorphosed into a species of frog called $\mathrm{Hy}$ perolius nasatus in 45 days. 
Table 1: Mouthpart characteristics of tadpoles in group A (Bufo regularis)

\begin{tabular}{ll}
\hline Structure & Description \\
\hline Oral disc: & Emarginate as in fig.1a \\
Jaw sheath: & Serrate, Valley- saw toothed as in fig.1b \\
Labial Tooth row: & $2 / 3$ as in fig.1c \\
& Labial Tooth row formula (LTRF) $=2(2) / 3$ \\
\hline
\end{tabular}

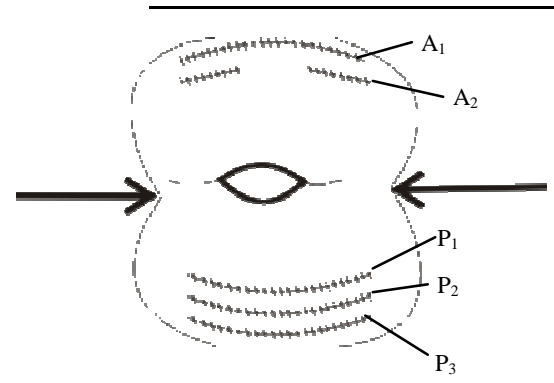

a) Oral Disc

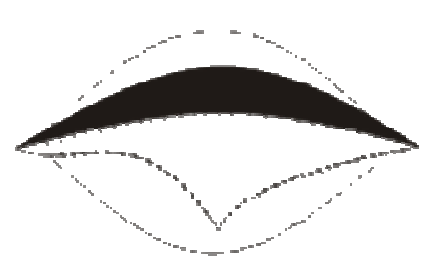

b) Jaw Sheath

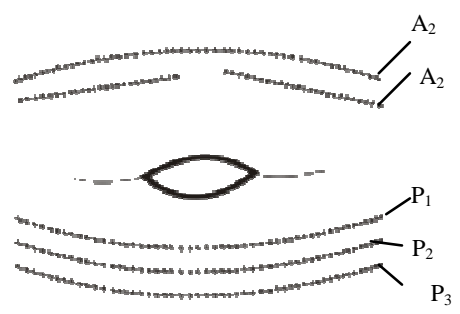

c) Labial Tooth Row

Fig. 1: Mouth part configuration of tadpoles in Group A (Bufo regularis) (P1= first posterior tooth row; $\mathrm{P2}=$ second posterior tooth row and $\mathrm{P3}=$ third posterior tooth row; $\mathrm{A} 1=$ first anterior tooth row; $A 2=$ second anterior tooth row).

Table 2: Mouthpart characteristics of tadpoles in group B (Hyperolius nasatus)

\begin{tabular}{ll}
\hline Structure & Description \\
\hline Oral disc: & Emarginate as in fig. $2 \mathrm{a}$ \\
Jaw sheath: & Cuspate pointed as in fig. $2 \mathrm{~b}$ \\
Labial tooth row (LTRF): & $3 / 3$ as in fig $2 \mathrm{c}$ \\
& Labial tooth row formula $(\mathrm{LTRF}):=3(2)(3) / 3(1)$ \\
\hline
\end{tabular}

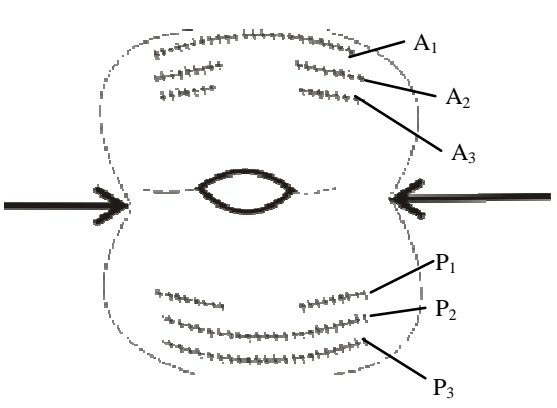

a) Oral Disc

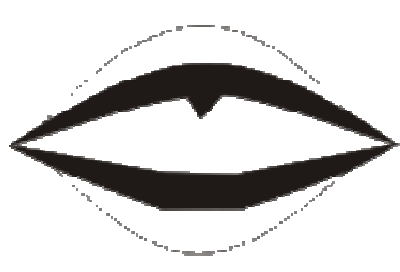

b) Jaw Sheath

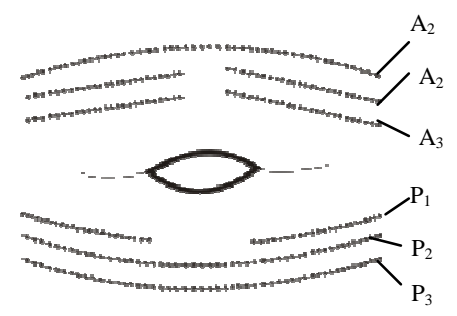

c) Labial Tooth Row

Fig. 2: Mouth part configuration of tadpoles in group B (Hyperolius nasatus) (P1= first posterior tooth row; $\mathrm{P2}=$ second posterior tooth row and $\mathrm{P3}=$ third posterior tooth row $\mathrm{A} 1=$ first anterior tooth row; $\mathrm{A} 2=$ second anterior tooth row; $\mathrm{A} 3=$ third anterior tooth row). 


\section{DISCUSSION}

The tadpoles in group A that had an average body length of $1.2 \mathrm{~cm}$ eventually, after metamorphosis that lasted 22 days produced young toads which were identified to be of the same species, Bufo regularis. Their tadpoles showed very interesting characteristic features especially with the jaw sheath and labial tooth rows. The oral disc was emarginate and the sheath appeared rather unfamiliar as compared with earlier works carried out especially in Canada and USA (McDiarmid and Altig, 2001). The jaw sheath appeared in the form of a valley and was therefore labelled as serrate and valley-saw toothed. Bufo species are cosmopolitan in distribution but highly abundant in the Savanna areas southwards from the Sahara, West and South Africa to Angola, Botswana and Mozambique (Stewart, 1867).

The tadpoles in group B that had an average body length of $1.3 \mathrm{~cm}$ and a jaw sheath that appeared cuspate and pointed with gaps in the second and third rows of the anterior labial tooth rows but just a gap in the first of the posterior labial tooth rows eventually produced frog-lets which were identified to be Hyperolius nasatus. Hyperolius nasatus is abundant in Savanna areas southwards from the Sahara, West and South Africa to Angola, northern Botswana, Mozambique and Natal lowlands (Stewart, 1967).

\section{CONCLUSION}

From the study Hyperolius nasatus and Bufo regularis were identified based on the mouth part characteristics of their tadpoles; the labial tooth row formula of $H$. nasatus tadpoles was 3(2) (3)/3(1) and that of $B$.regularis tadpoles was 2 (2)/3. Thus it is possible to identify toads and frogs based on the mouth part characteristics of their tadpoles.
The challenge is for scientist in Africa especially Ghana to research and develop a 'key system' for African tadpoles. Often tadpoles are seen in pools in the bush without seeing the adults themselves; it is possible that with just a hand lens in hand one can identify a species of toad or frog in the field without having to look for the adult, rely on external characteristics that are often influenced by environmental factors.

\section{REFERENCES}

Barry, S.J. and Schaffer, H. B. (1994).The status of the California Tiger Salamander (Ambystoma californiense) at Lagunita: A fifty-year update. Journal of Herpetology. 28: 139-164.

Horst, J. (1963). Pond Life in the Aquarium, Studio vista, London, pp 58

Jennings, R. D. and Scott, J. K. (1993). Ecologically correlated Morphological Variation in tadpoles of the leopard frog, Rana chiricahuensis, Journal of Herpetology 7: 143-147

McDiarmid, R. W. and Altig, R (2001).Biology of Anuran Larvae, University of Cambridge Press, USA. pp78

Orton, G. (1953).The systematic of vertebrate larvae. Syst. Zool. 2: 63-75.

Stewart, M. (1967). Amphibian of Malawi. Longmans, London. pp146 